\title{
Implementation of Lean Principles for Performance Improvement: Use of VSM+WID for Waste Identification
}

\author{
J. Dinis-Carvalho ${ }^{1}$, R. M. Chandima Ratnayake ${ }^{2}$, L. Ferrete $^{1}$ \\ ${ }^{1}$ Department of Production and Systems, Algoritmi Centre, University of Minho, Guimarães, Portugal \\ ${ }^{2}$ Department of Mechanical and Structural Eng. and Materials Science, University of Stavanger, Stavanger, Norway \\ (dinis@.dps.uminho.pt, chandima.ratnayake@uis.no, luis53978@gmail.com)
}

\begin{abstract}
This article demonstrates the implementation of lean principles for performance improvement in a manufacturing firm. Value stream mapping and waste identification diagrams (VSM+WID) are integrated to assess the level of currently existing waste and the overall current status of the manufacturing flow. The VSM+WID enables an increase in the awareness of relative waste distribution among different processes in the selected case study manufacturing unit. This manuscript demonstrates how to use VSM+WID to understand the current status of the manufacturing flow related challenges such as: overproduction, work-in-process, inefficient use of man-hours (e.g. unbalanced work distribution), etc. It also demonstrates the effectiveness of visualization of the performance gap between the current and future state. The aforementioned type of performance assessment enables effective identification of waste present in a manufacturing flow in order for future improvement initiatives to be taken.
\end{abstract}

Keywords - value stream mapping, waste identification diagram, manufacturing, performance improvement

\section{INTRODUCTION}

The International Labour Organization (ILO) recognizes the need to assist in the implementation and coordination of actions to improve working conditions and productivity in the textiles, clothing, leather and footwear (TCLF) industrial sector [1]. The TCLF industrial sector plays a key role in Europe and also worldwide, especially in the lesser developed economies, contributing to wealth generation and employment $[1,2]$. During recent years, the TCLF manufacturing industry has faced major challenges, especially due to rising demands to cut the prices of readymade products [2]. Hence, to remain competitive, it is vital to follow lean manufacturing concepts to maintain: continuous improvement, elimination of waste, efficient use of resources, teamwork, etc. in the TCLF industrial sector [3].

The lean manufacturing approach offers an integrated sociotechnical system and management practices that can be used for the elimination of waste in terms of minimizing variability in internal resources and processes, suppliers' deliverables, and customers' requirements [4]. However, most organizations face difficulty in attaining significant improvements due to the lack of understanding of both lean manufacturing concepts and the real practical significance (or purpose) of currently existing lean practices $[5,6]$. Some lean concepts' misapplications include "use of wrong tool to solve a problem", "use of single tool to solve all the problems", and "use of the same set of tools on each problem" $[4,7]$. Hence, it is vital to investigate how to use the salient features of different lean tools for effective performance improvements in manufacturing firms.

This manuscript demonstrates how to use the salient features of the lean tools, value stream mapping (VSM) [8] and waste identification diagram (WID) [9], to improve the performance of a manufacturing unit in a leather products' manufacturing firm. The VSM+WID diagram enables visualization of the gap between the current level of waste and performance (i.e. current state) and the anticipated level (i.e. future state). The aforementioned kind of visualization opens practitioners' eyes to the amount of waste that could be reduced, whilst encouraging them to search for effective solutions for reducing waste.

\section{BACKGROUND OF THE CASE STUDY MANUFACTURING FIRM}

The leather cutting section of a leather products manufacturing firm is selected for the case study (i.e. for waste visualization via VSM+WID). The cut leather pieces are assembled in another area in the same manufacturing firm. The throughput of this production unit is about 490 $\mathrm{m}^{2}$ of leather per day; 121 workers are employed in three shifts, distributed as follows:

- 44 workers involved in cutting operations, using three large presses, together with six large tables for cutting tools' positioning

- 22 workers involved in inspection after cutting

- 6 workers involved in moving leather pieces to temporary storage

- 14 workers involved in facing operations (grinding a chamfer to facilitate sewing operations)

- 21 workers involved in lamination operations (gluing a layer of foam on the back of every leather piece, using special machines)

- 14 workers involved in final inspection.

The semi-finished leather products are then moved to another unit in the same manufacturing firm, where they are sewn to create final ready-made products. 


\section{METHODOLOGY}

\section{A. VSM and WID}

The Waste Identification Diagram (WID) [9] was created to represent production units in greater detail and

\section{DEFINITION OF THE TEAM AND PRODUCTION UNIT (PHASES $1 \&$ 2)}

The first phase of the methodology is the definition of the team responsible for the improvement project (i.e. the focus of the case study). The improvement project was

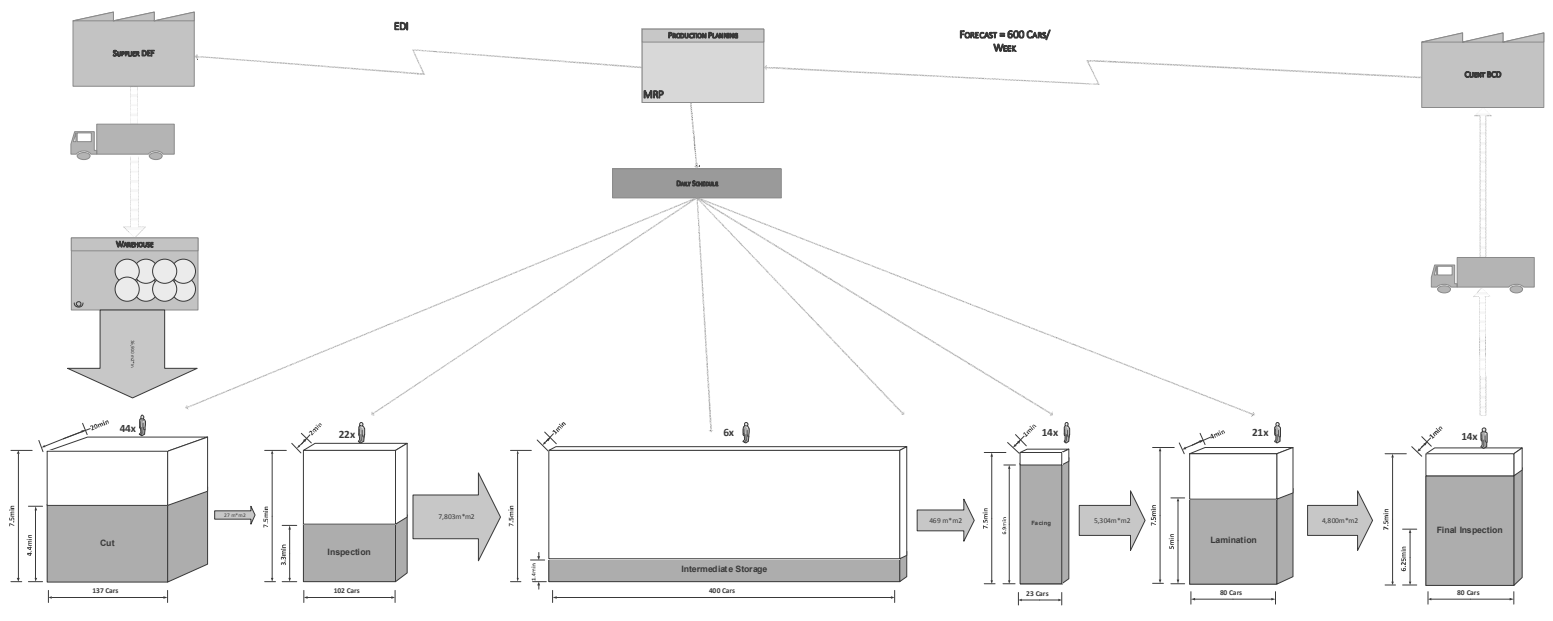

Fig. 1. VMS+WID of the current condition.

in a more effective visual way than the popular Value Steam Maps (VSM). Another version of WID was created [10] to take advantage of the information flow features of the VSM and to facilitate the understanding of these tools for VSM users. This version of WID was coined as VSM+WID and takes the best visual effect features of the WID plus the more understandable material and information flow of the VSM.

\section{B. Work Process}

The work process that has been used to implement lean manufacturing concepts consists of the following phases and associated activities.

- Phase 1 - Definition of the team

- Phase 2 - Definition of the production unit boundaries, upon which improvement should take place

- Phase 3 - Data collection, analysis and diagnosing the defined production unit, using VSM+WID and Multi-Moment analysis

- Phase 4 - Identification and implementation of improvement opportunities

- Phase 5 - For each improvement opportunity

○ Generate alternative solutions

- Select the best solution

- Implement the solution selected

- Phase 6 - Analyzing the results

- Phase 7 - Concluding and defining the next steps assigned to the existing continuous improvement team in the company, with five members, plus a new person, who led the project. The leader of the project occupied most of their time in this project, while the other members also spent time on operational functions, as well as other improvement projects carried out in other areas of the factory. The team had to hold regular weekly meetings to monitor the status of every improvement action and present the main achievements to the top management each month.

The second phase was the definition of the production unit boundaries, upon which improvement should take place.

\section{DATA COLLECTION, ANALYSIS AND DIAGNOSES VIA VSM+WID (PHASE 3)}

In this third phase, the team leader proposed the use of two new tools, VSM+WID and Multi-Moment analysis. In order to effectively grasp the current state of the production unit, the VSM+WID mapping tool was used. A shrunk version of the real VSM+WID is presented in Fig. 1. Since it is very difficult to read the details of this map, some parts will be amplified as necessary throughout this article.

Analyzing the VSM+WID and performance indicators revealed that:

- Maximum levels of work in process (WIP) are located in an intermediate stock stored before the "facing" process with 400 cars, resulting in an average of 50 hours' storage time.

- Significantly unbalanced system (see Fig. 2). 


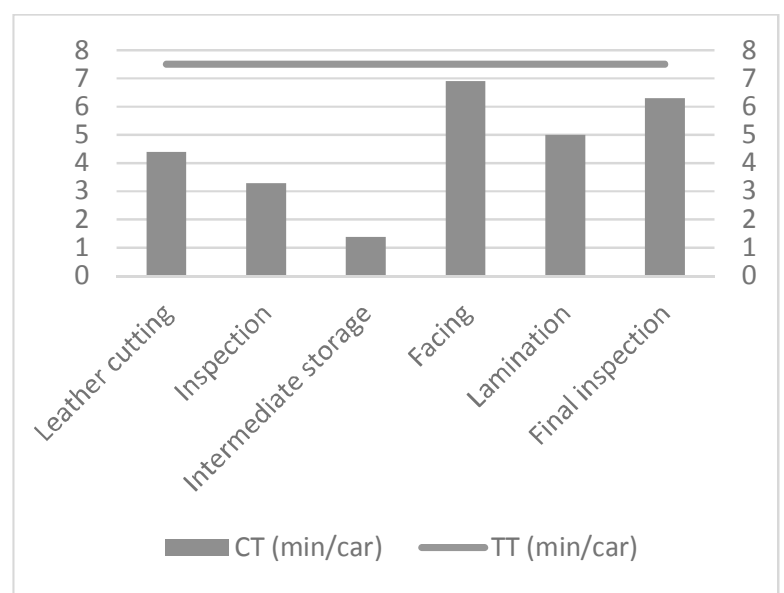

Fig. 2. Unbalanced load in different processes.

Some processes' cycle times are quite far from the takt time. Both cycle time and takt time are measured in minutes per car, where a car is $2.55 \mathrm{~m}^{2}$ of leather.

- Systems efficiency

Systems efficiency measures how balanced a system is. If all cycle times are equal to takt time, then system efficiency is $100 \%$.

$$
\text { Systems Efficiency }=\frac{\begin{array}{c}
\text { Sum of all operations' } \\
\text { cycle times }
\end{array}}{\text { Number of processes }} \times \text { Takt time }
$$

The systems efficiency of this production unit is $60.7 \%$.

- Workers' time spent in non-value-adding activities A multi-moment analysis [11] was performed in the cutting processes; the results are presented in Table I.

TABLE I

\begin{tabular}{|c|c|c|c|c|}
\hline Task & 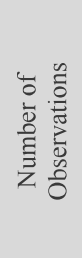 & 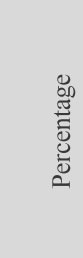 & 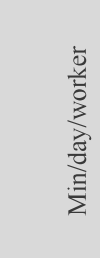 & 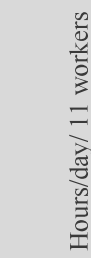 \\
\hline $\begin{array}{l}\text { Value } \\
\text { Adding }\end{array}$ & 121 & $30 \%$ & 115.02 & 21.09 \\
\hline Waiting & 114 & $28 \%$ & 108.37 & 19.87 \\
\hline Transport & 85 & $21 \%$ & 80.80 & 14.81 \\
\hline Motion & 57 & $14 \%$ & 54.19 & 9.93 \\
\hline Rework & 28 & $7 \%$ & 26.62 & 4.88 \\
\hline Total & 405 & $100 \%$ & 385 & 70.58 \\
\hline
\end{tabular}

RESULTS OF THE MULTI-MOMENT ANALYSIS

Although the shift time is 450 minutes, the available time per shift for production is 385 minutes (see last row in Table 1). In fact, the workers spend approximately 20 minutes at the beginning of every shift preparing tools and
45 minutes at the end of the shift counting parts, arranging tools on shelves, and labeling.

- High setup time in the leather cutting process

The 20-minute setup time required in the leather cutting process is the highest of all the involved processes. This is a problem that shall be improved.

\section{- Value added ratio}

The value added ratio compares the time products spent in operations with the throughput time.

$$
\text { Value Added Ratio }=\frac{\sum \text { Value Added times }}{\text { Throughput time }}
$$

It shows that part of the time spent by the products in the system is actually used in operations. In this case the value is 102.75 hours. Since the total time in operations is 27.3 min, the $\mathrm{VAR}=0.44 \%$, very small value compared with the reference value of $5 \%$.

\section{- Productivity}

The current value of productivity is $0.32 \mathrm{car} / \mathrm{man}$-hour. This does not mean much, since there is no reference to compare it to, but it is the current value that must be improved.

\section{- Cut efficiency}

This indicator measures the percentage of the available leather area in $\mathrm{m}^{2}$ of a given leather sheet, which is actually used in parts. This value measures the level of leather wasted during the cutting. The way the parts are distributed on a sheet of leather is a key issue in improving this efficiency indicator. The current value is $60.5 \%$

A summary of performance indicators is illustrated in Table II.

TABLE II

\section{PERFORMANCE INDICATORS IN THE CURRENT CONDITION}

\begin{tabular}{lc}
\hline \multicolumn{1}{c}{ Performance Indicator } & Value \\
\hline Throughput time (hours) & 102.75 \\
Transportation effort $\left(\mathrm{m}^{2 *} \mathrm{~m} /\right.$ day) & 55808 \\
Value added ratio (\%) & $0.44 \%$ \\
Manpower utilization in VA (\%) & $30 \%$ \\
System efficiency (\%) & $60.7 \%$ \\
Smoothness index & 8.52 \\
Productivity (cutting and inspection) (car/man-day) & 12.2 \\
\hline
\end{tabular}

\section{IDENTIFICATION AND IMPLEMENTATION OF IMPROVEMENT OPPORTUNITIES (PHASES 4 \& 5)}

It is possible for the team to identify a number of problems and improvement opportunities with the support of VSM+WID in Fig. 1. These are described as follows: 


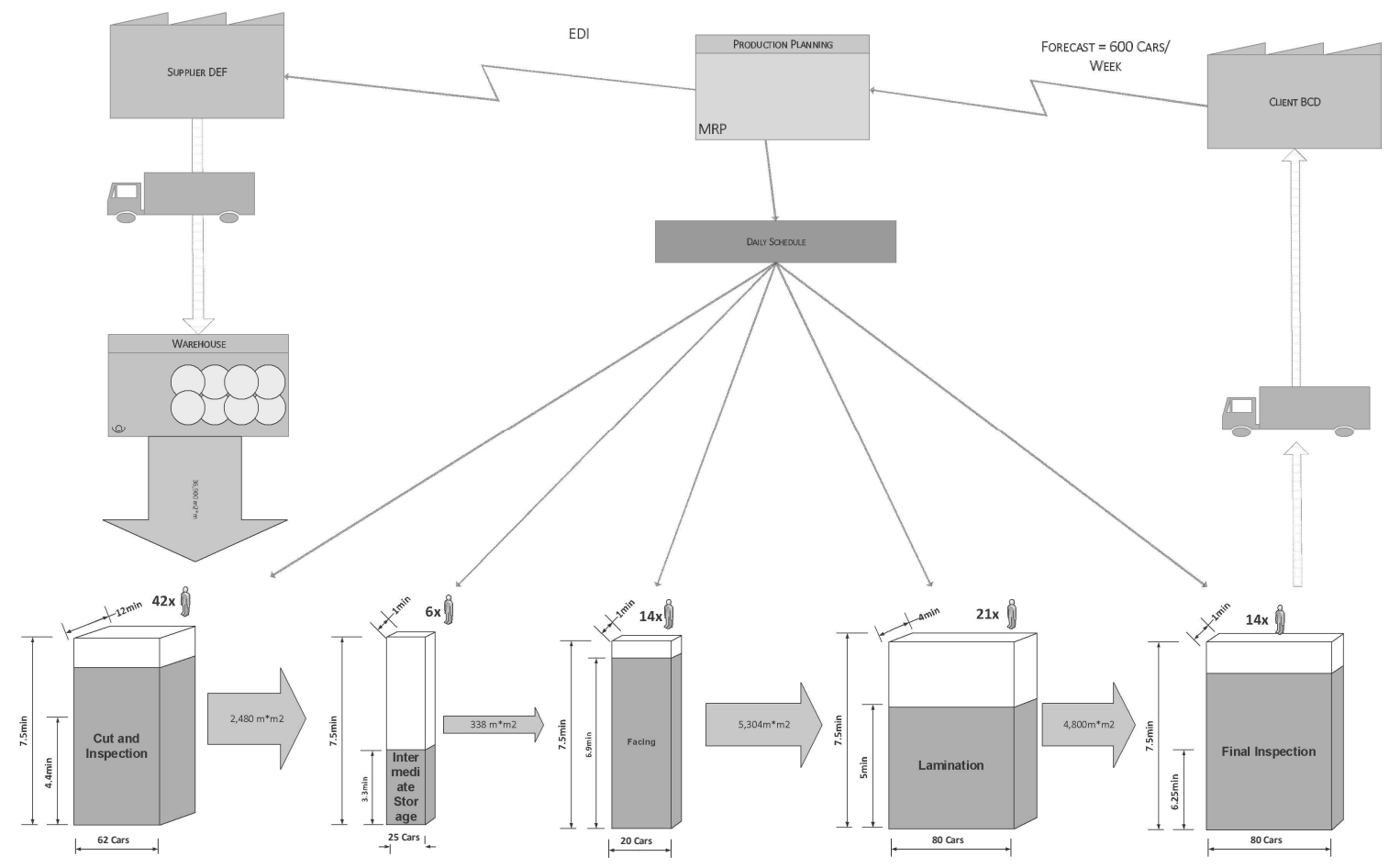

Fig. 3. VSM+WID future state.

\section{A Improving Flow and Reducing WIP}

At a glance, it is evident from Fig. 1 that there is unnecessary waste associated with work in process (WIP) as 'intermediate storage' (or buffer stock). Investigation revealed that an inappropriate planning process resulted in the need for intermediate storage, causing unnecessary waste due to WIP. For instance, currently the production planner receives production orders for one week and all of them have been assigned during the cutting planning process to improve cutting efficiency. The aforementioned has resulted in the processing of some orders before they are needed, ultimately resulting in accumulating unnecessary WIP and necessitating intermediate storage, as the cut pieces have to wait in a queue for the subsequent operations. In order to optimize WIP, the planning rules were changed; however, as a result, the number of setups was increased. To overcome challenges pertaining to the increased number of setups, it is necessary to reduce the setup time. It is possible to reduce the setup time by using the Single-Minute Exchange of Die (SMED) approach.

\section{$B \quad$ Restructuring Cutting and Inspection Operations}

The inventory between cutting and inspection was eliminated, with the operators performing inspections as the parts are removed from the cutting table. This change eliminated the inventory and reduced motion as well. The pieces were thrown to trays and then had to be counted before they were transported to the intermediate store. Now the pieces are put in trays in batches of 10, eliminating the need for further handling of pieces. The standards for cutting and inspection were redesigned in order to reduce motion, transportation and waiting wastes as well as inventory by improving flow.

\section{Layout to Reduce Several Types of Waste}

A new layout was defined in order to reduce the distances that the materials had to travel between workstations. In some cases, certain machines just had to be rotated 90 and 180 degrees to reduce the distances traveled. The areas for storage were also changed, and some machines had to be moved to different locations. In one case, a press was removed from the area because the team found that it was not needed anymore. This new layout allowed a more linear flow from raw materials to end products.

\section{Mizusumashi, Supermarket and Border of Line}

A new flow system was implemented to improve flow and reduce WIP. This flow system includes a supermarket after the cut and inspection workstations, a mizusumashi to transport the materials in a systematic way and boards of line with gravity racks next to the facing machines. A supermarket had to be created with appropriate racks to store the parts supplied by the various cut and inspection workstations. A fixed route was defined for the mizusumashi, with a standard cycle time of two hours. This cycle time was estimated and tested to allow all the operations: collecting the parts from the supermarket, transport, and putting the parts in the several boards of line racks of the facing machines. 


\section{ANALYZING THE RESULTS}

The improvement actions were mainly focused on the first three processes: cutting, inspection, and intermediate storage, as well as on the logistics related to the supplying of parts to the facing process. After the improvements, the VSM+WID future state was as presented in Fig. 3.

Regarding the first processes, cutting and inspection, the evolution of the productivity after the implementation of the changes is shown in Fig. 4.

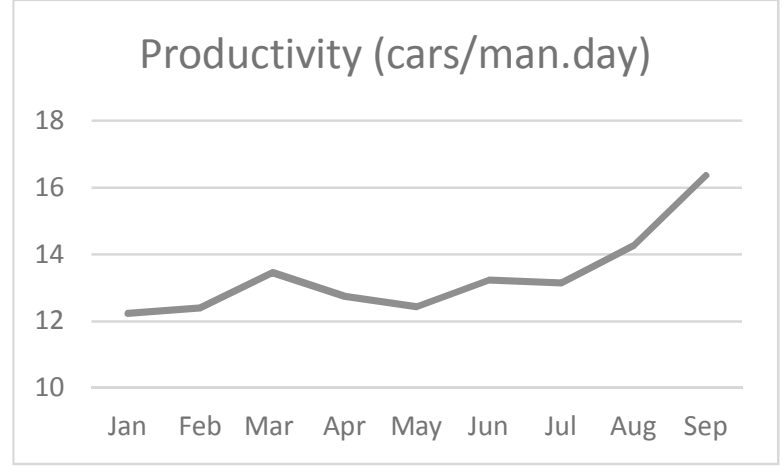

Fig. 4. Evolution of cut and inspection productivity after improvements.

Other results regarding performance improvement are shown in Table III.

\section{TABLE III}

IMPROVEMENTS IN PERFORMANCE INDICATORS

\begin{tabular}{|c|c|c|c|}
\hline Performance Indicator & 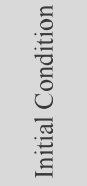 & 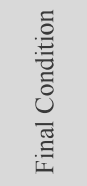 & 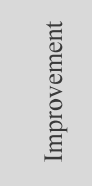 \\
\hline Throughput time (hours) & 103 & 33 & $-68 \%$ \\
\hline $\begin{array}{l}\text { Transportation effort } \\
(\mathrm{m} 2 * \mathrm{~m} / \text { day })\end{array}$ & 18403 & 13426 & $-27 \%$ \\
\hline Value added ratio (\%) & $0.44 \%$ & $1.8 \%$ & $+197 \%$ \\
\hline $\begin{array}{l}\text { Manpower utilization in VA } \\
(\%)\end{array}$ & $30 \%$ & $37 \%$ & $+23.3 \%$ \\
\hline System efficiency (\%) & $60.7 \%$ & $70.4 \%$ & $+16 \%$ \\
\hline Smoothness index & 8.52 & 6.76 & $-20 \%$ \\
\hline $\begin{array}{l}\text { Productivity (cutting and } \\
\text { inspection) (car/man-day) }\end{array}$ & 12.2 & 16.4 & $34 \%$ \\
\hline
\end{tabular}

\section{DISCUSSION AND CONCLUSION}

This article presents the use of a lean methodology based on VSM, which is enhanced with WID features in order to improve the diagnosing process and improve the way a production unit is described. The methodology was applied in a leather-cutting unit in a manufacturing firm, focusing on the identification of several improvement opportunities, as well as the design and implementation of solutions. The achieved performance improvements are significant and impressive. The throughput time decreased by $68 \%$, allowing faster deliveries, as well as improving the value-added ratio by $197 \%$. One buffer was eliminated by combining cutting and inspection into a single process. The productivity of the cutting and inspection process improvement $34 \%$, which is very important due to the fact that this process involves the majority of the workers. The utilization of people in value-adding operations increased from an initial value of $30 \%$ to a final value of $37 \%$. This value is still very low because the nature of this production unit requires many operations which do not add any value, such as positioning and inspecting.

A continuous improvement system must be implemented now in this production unit in order to maintain the ongoing search for solutions leading to further improvements.

\section{ACKNOWLEDGMENT}

This work has been supported by COMPETE: POCI01-0145-FEDER-007043 and FCT - Fundação para a Ciência e Tecnologia within the Project Scope: UID/CEC/00319/2013.

\section{REFERENCES}

[1] ILO, "Wages and Working Hours in the Textiles, Clothing, Leather and Footwear Industries," International Labour Organization, GDFTCLI/2014, http://www.ilo.org/wcmsp5/groups/public/@ed dialogue/@sector/documents/publication/wcms 300463.pdf, 2014. (accessed on 23.05.2017).

[2] M. Bruce, L. Daly, and N. Towers, "Lean or agile: A solution for supply chain management in the textiles and clothing industry?" Int. J. Oper. Prod. Man., vol. 24, no. 2, pp.151-170, 2004.

[3] D. Raj, Y. J. Ma, H. J. Gam, and J. Banning, "Implementation of lean production and environmental sustainability in the Indian apparel manufacturing industry: a way to reach the triple bottom line," Int. J. Fashion Design, Technology and Education, http://dx.doi.org/ 10.1080/ 17543266.2017.1280091, 2017.

[4] S. Mostafa, J. Dumrak, and H. Soltan, "A framework for lean manufacturing implementation," Prod. Manuf. Res., vol. 1, no.1, pp. 44-64, 2013.

[5] J. H. Marvel, and C. R. Standridge, "Simulation-enhanced lean design process," J. Ind. Eng. Manage., vol. 2, pp. 90-113, 2009.

[6] R. M. Chandima Ratnayake, and O. Chaudry, "Maintaining sustainable performance in operating petroleum assets via a leansix-sigma approach: a case study from engineering support services," Int. J. Lean Six Sigma, vol. 8, no. 1, pp. 33-52, 2017.

[7] S. J. Pavnaskar, J. K. Gershenson, and A. B. Jambekar, "Classification scheme for lean manufacturing tools", Int. J. Prod. Res., vol. 41, pp. 3075-3090, 2003.

[8] M. Rother, J. Shook, J. Womack, and D. Jones, Learning to See: Value Stream Mapping to Add Value and Eliminate MUDA, Spi Edition. Cambridge, MA USA: Lean Enterprise Institute, 1999.

[9] J. Dinis-Carvalho, F. Moreira, S. Bragança, E. Costa, A. Alves, and R. Sousa, "Waste identification diagrams," Prod. Plan. Control, vol. 26, no. 3, pp. 235-247, 2015.

[10] J. Dinis-Carvalho, L. F. Ferrete, R. M. Sousa, H. S. Medeiros, A. J. Magalhães, and J. P. Ferreira, "Process mapping improvement: extending value stream maps with waste identification diagrams," FME Trans. Faculty of Mechanical Engineering, vol. 43, no. 4, pp. 287-293, 2015.

[11] MMA, "What is a Multi Moment Analysis (MMA)", 2017. https://multimomentanalysis.com/en/what-is-a-multi-moment analysis -mma.html (accessed on 29.05.2017). 